\title{
Hematopoietic Cell Transplant and Use of Massage for Improved Symptom Management: Results from a Pilot Randomized Control Trial
}

\author{
Wolf E. Mehling, ${ }^{1,2}$ E. Anne Lown, ${ }^{3}$ Christopher C. Dvorak, ${ }^{4}$ Morton J. Cowan, ${ }^{4}$ \\ Biljana N. Horn, ${ }^{4}$ Elizabeth A. Dunn, ${ }^{4}$ Michael Acree, ${ }^{1}$ Donald I. Abrams, ${ }^{1,5}$ \\ and Frederick M. Hecht ${ }^{1,6}$ \\ ${ }^{1}$ Osher Center for Integrative Medicine, University of California, San Francisco, CA 94115, USA \\ ${ }^{2}$ Department of Family and Community Medicine, University of California, San Francisco, CA 94115, USA \\ ${ }^{3}$ Alcohol Research Group, Public Health Institute, Emeryville, CA 94608, USA \\ ${ }^{4}$ Blood and Marrow Transplant Division, Department of Pediatrics, University of California, San Francisco, CA 94143, USA \\ ${ }^{5}$ Department of Medicine, Hematology and Oncology, University of California, San Francisco, CA 94110, USA \\ ${ }^{6}$ Department of Medicine, University of California, San Francisco, CA 94115, USA
}

Correspondence should be addressed to Wolf E. Mehling, mehlingw@ocim.ucsf.edu

Received 7 August 2011; Revised 5 November 2011; Accepted 13 November 2011

Academic Editor: Andrew Scholey

Copyright (C) 2012 Wolf E. Mehling et al. This is an open access article distributed under the Creative Commons Attribution License, which permits unrestricted use, distribution, and reproduction in any medium, provided the original work is properly cited.

\begin{abstract}
Background. Pediatric hematopoietic cell transplant (HCT) is a lifesaving treatment that often results in physical and psychological discomfort. An acupressure-massage intervention may improve symptom management in this setting. Methods. This randomized controlled pilot trial compared a combined massage-acupressure intervention to usual care. Children were offered three practitioner-provided sessions per week throughout hospitalization. Parents were trained to provide additional acupressure as needed. Symptoms were assessed using nurses' reports and two questionnaires, the behavioral affective and somatic experiences scale and the Peds quality of life cancer module. Results. We enrolled 23 children, ages 5 to 18 . Children receiving the intervention reported fewer days of mucositis (Hedges' g effect size ES $=0.63$ ), lower overall symptom burden $(\mathrm{ES}=0.26)$, feeling less tired and run-down $(\mathrm{ES}=0.86)$, having fewer moderate/severe symptoms of pain, nausea, and fatigue $(\mathrm{ES}=0.62)$, and less pain $(E S=0.42)$. The intervention group showed trends toward increasing contentness/serenity $(E S=+0.50)$ and decreasing depression $(\mathrm{ES}=-0.45)$, but not decreased anxiety $(\mathrm{ES}=+0.42)$. Differences were not statistically significant. Discussion. Feasibility of studying massage-acupressure was established in children undergoing HCT. Larger studies are needed to test the efficacy of such interventions in reducing HCT-associated symptoms in children.
\end{abstract}

\section{Introduction}

Hematopoietic cell transplant (HCT) can be a lifesaving treatment for cancer and other disorders. Despite advances in supportive care children suffer considerable physical and psychological discomfort during their hospitalization for HCT. Nonpharmacological means of symptom management are attractive adjuncts to care given their generally lower risk for additional side effects. However, there are limited data on such interventions in this patient population.
Massage, borrowed from both Western and Eastern traditions, is a noninvasive modality to reduce symptom burden including pain, nausea, and anxiety. Massage studies have suggested benefits for oncology patients, [1-12] pediatric patients $[13,14]$ and for HCT recipients, adult [15] as well as pediatric [16], but the results from smaller studies of pediatric HCT recipients were not confirmed in a larger study [17]. Large observational studies of massage in adult cancer patients suggest benefits in the short and long term [1] but these findings are limited by the lack of a randomized control group. 
Massage methods commonly used in cancer care include Western (Swedish) and Eastern (acupressure) massage styles $[18,19]$. Both styles are increasingly being combined [20] but this combination has not been previously studied.

Acupressure massage, the manual stimulation of specific acupuncture points commonly used in traditional Chinese medicine, can reduce chemotherapy-associated nausea $[8$, $15,21-24]$, vomiting [25], anxiety, and fatigue [15, 26], and its use by massage practitioners has been increased in Europe [19, 27, 28] and the US [29]. A Cochrane review concluded that acupressure may be a low-cost, convenient, easily administered intervention for chemotherapy patients to reduce acute nausea [21]. Acupressure massage can be successfully taught to both patients and caregivers [30] and shows benefits for postoperative nausea in children in a meta-analysis [31]. Western massage is effective in reducing anxiety and pain $[32,33]$ mostly in the short term $[34,35]$, and cumulative or long-term effects have been reported [36].

Caregivers of family members with cancer experience high levels of distress [16, 37, 38], particularly mothers [3942]. Frequently, parents of children with cancer experience symptoms of posttraumatic stress disorder (PTSD) [43, 44] with related health problems [45]. During the HCT process parents report feeling helpless in the face of their child's pain and suffering $[43,44]$. This helplessness is a key risk factor for the development of PTSD [46]. Parental distress increases the risk for posttraumatic stress symptoms [47] and other adjustment problems in the child [48-50].

If parents are taught to perform massage on their children, both patient and caregiver may benefit. Parents who provide massage for sick children report reduced distress [16, 51, 52]. Parents reported improved self-efficacy in managing their child's symptoms, decreased anxiety, and decreased stress when they massaged their sick children [53-55].

The aims of the present study were (a) to determine feasibility of a practitioner-provided combined massage and acupressure intervention for children undergoing HCT with parent training for additional parent-provided massages and (b) to collect preliminary data on the efficacy of this intervention for decreasing treatment-related symptoms such as nausea, vomiting, and pain. A secondary aim explored whether training parent caregivers to provide massage decreased parents' perceived stress and psychological distress and improved their sense of self-efficacy.

\section{Methods}

We conducted a randomized, nonblinded pilot study of a massage/acupressure intervention compared to usual care for pediatric patients undergoing HCT at an academic medical center. Imbalanced randomization $(2: 1)$ was used, stratified by allogeneic versus autologous transplantation, with more persons randomized to the massage/acupressure intervention to allow greater assessment of the feasibility of the intervention arm in this setting. Participants and study staff were aware of the group assignment. The study was approved by the university's Human Subjects Review Committees, and informed consent was obtained from participant's parents, and assent from participants over age 12. The study was registered with clinical trials.gov NCT00843180.

2.1. Patients. At the preadmission intake visit for HCT treatment, twenty-five consecutive children aged 5 to 18 years and their parents were invited to participate in the massage study. Twenty-three patients consented ( $92 \%$ response rate). Study personnel used sealed opaque envelopes that contained the computer-generated intervention or usual care group assignment. The envelopes were opened on the first day of hospital admission after baseline assessment was completed.

2.2. Intervention. Two experienced ( $>10$ years) professional massage practitioners provided 20-30 minutes of semistandardized and manualized combined Swedish and acupressure massage three times a week in the patient's room over the entire duration of the hospital stay. Practitioners utilized: (a) a semistandardized Swedish-style massage for feet, legs and arms, and, when feasible, for back and shoulder girdle; (b) acupressure massage used specific pain, nausea, and calming acupressure points selected based on prior research [56-58] and consultation with acupuncture experts: Pericardium 6 (wrist) and Stomach 36 (below the knee) for nausea; Triple Warmer 5 (wrist) for stress; Large Intestine 4 (hand) and Liver 3 (foot) for pain; Kidney 6 and Bladder 62 (ankle) for nausea/stress; Spleen 6 (above the ankle) for stress. The practitioners instructed parents on how to use acupressure on their child demonstrating point location on the child and on the parent (for purposes of learning the point location) and using an instruction sheet with pictures, location descriptions, and indications for 9 selected points. Parents were encouraged to perform additional acupressure on their child for improved and timely symptom management.

Control subjects received usual care: state-of-the-art medical treatment for HCT with pharmaceutical symptom management for pain and nausea but no massages or acupressure. They were offered a single 20-minute massage each for parent and child in the days before discharge and separate \$25 gift cards for child and parent after completion of all questionnaires.

2.3. Measures. Two types of data were collected in both groups: nurse's daily clinical records and questionnaire data. Questionnaires were administered to both parents and children to assess the child's physical and psychological symptoms. Parents also answered questions about their own wellbeing. Nurses' clinical data included information for each day on: nausea, number of vomiting episodes, pain, and mucositis. Most were assessed at multiple points during the day. Data were collected on days of hospital stay and days to absolute white cell and neutrophil count greater than 500 cells $/ \mathrm{mm}^{3}$ for 3 consecutive days.

Questionnaires were administered to children and parents by the research assistant at baseline and then every two weeks. One week after discharge from inpatient care, the parent was interviewed over the phone. Questionnaires for children age 5-7 used simplified response options and face symbols. Data in the current report are based on child report. 
Physical symptoms and psychological states were assessed using the BASES and PedsQL. The behavioral affective and somatic experiences scale (BASES) is a 22-item instrument developed at St. Jude Children's Research Hospital specifically for the assessment of child distress during hospitalization for HCT. Independent subscales measure somatic distress, compliance, mood/behavior (anxious, depressive), interactions, and activity. Both child and parent report BASES were used $[59,60]$. To decrease patient burden, we reduced the number of items to 18 by dropping two less relevant subscales (compliance, interactions). The PedsQL Cancer Module [61, 62] is a 28-item modular quality of life measure for children with cancer. The cancer module is appropriate for an inpatient setting and includes versions for age groups: 5-7, 8-12, and 13-18 years old and for parents. It includes eight independent subscales; we used those corresponding to problems with pain (2 items), nausea (5), procedural anxiety (3), and worry (1), thereby reducing the number of items to 12. Positive affect was measured using four items selected from the differential emotions scale (DES) [63].

Parents were given an additional questionnaire administered at baseline and in the week following discharge from the hospital. The questionnaire included the CES-D [64] measure of depression [65] and the parent's self-efficacy scale [53] (PSES), which assessed self-efficacy of managing their child's symptoms. Posttraumatic stress symptoms were assessed using the PTSD symptom scale [66] (PSS) [67].

2.4. Outcomes. Primary outcomes included symptoms of fatigue, nausea, vomiting, and pain. Secondary outcomes included mucositis and worry/anxiety. Several composite variables were derived from the nurses' daily clinical notes and from parent and child questionnaire data. The primary composite variable was derived classifying moderate-severe symptoms using the three key symptoms of pain, nausea, and fatigue using child self-report data from the BASES subscales. A second summary measure was derived from nurses' data and included number of days of any pain $>3$ (on a scale of 1-10), any nausea, any vomiting, and any mucositis.

2.5. Analyses. Analysis of the data was performed using SAS version 9.2. We compared baseline data between groups to assess the success of randomization by demographic and cancer characteristics and psychological status using chi square statistics. Physical symptom scores measured by questionnaire and nurses' clinical records were compared in intention-to-treat analyses using $t$-tests. Nurses' multiple daily electronic medical records were used for the time period of 7 days before to 21 days after-transplant and children's self-report data at baseline and one week after transplant. As the intervention in this pilot study was provided during the children's entire hospital stay, outcome measures were collected during the entire hospital stay as well in order to assess the feasibility of data collection in this setting. However, for the purpose of providing efficacy data on effect sizes needed for sample-size calculations for a larger study, we limited the analysis of children self-report data to a narrower period, as patients began getting discharged
TABLE 1: Patient characteristics.

\begin{tabular}{lcc}
\hline & Intervention & Control \\
\hline $\begin{array}{l}N \text { (intention to treat): } \\
\text { Demographics }\end{array}$ & 16 & 7 \\
$\quad$ Age (mean) (Range 5-18) & 11.3 & 13.9 \\
Sex & & \\
$\quad$ Female & 7 & 3 \\
$\quad$ Male & 9 & 4 \\
Ethnicity & & \\
$\quad$ White & 9 & 2 \\
Asian & 3 & 5 \\
Hispanic & 3 & 0 \\
$\quad$ Other & 1 & 0 \\
Diagnoses & & \\
Congenital or acquired & 5 & 0 \\
Bone marrow failure & & \\
$\quad$ Hematologic malignancy & 6 & 5 \\
Congenital immune deficiency & 3 & 1 \\
$\quad$ Solid tumor & 2 & 0 \\
$\quad$ Hemoglobinopathy & 0 & 1 \\
Transplant type & & \\
$\quad$ Autologous & 13 & \\
Allogeneic & & \\
\hline
\end{tabular}

before the self-report measures at 21 days were obtained. Standardized Hedges' g effect sizes were calculated taking uneven group sizes into account. Psychological status was assessed using change scores between baseline and one week following the transplant to control for baseline psychological state.

\section{Results}

Twenty-five children aged 5 to 18 years old and their rooming-in parents were admitted for HCT at the university children's hospital between November 2008 and December 2009 and invited to participate; 23 consented and enrolled. Patient characteristics are summarized in Table 1. Sixteen children were randomly assigned to the massage group and 7 to usual care (Figure 1).

During a median hospitalization of 41 days, children in the intervention group received a median of 8.5 massages averaging 1.6 massages per week. Fourteen of the 16 parents (87\%) reported performing massages on their children. Children and parents completed all requested surveys and a postdischarge telephone survey. No adverse side effects for the intervention were reported.

Five children were discharged from the hospital before the 3-week posttransplant survey; thus the focus of the data analysis is on the nurse's daily notes and the oneweek posttransplant self-report data. This small feasibility study was not expected to provide sufficient power to show statistically significant differences between groups; thus we report standardized effect sizes that allow for sample-size calculations for future studies. 


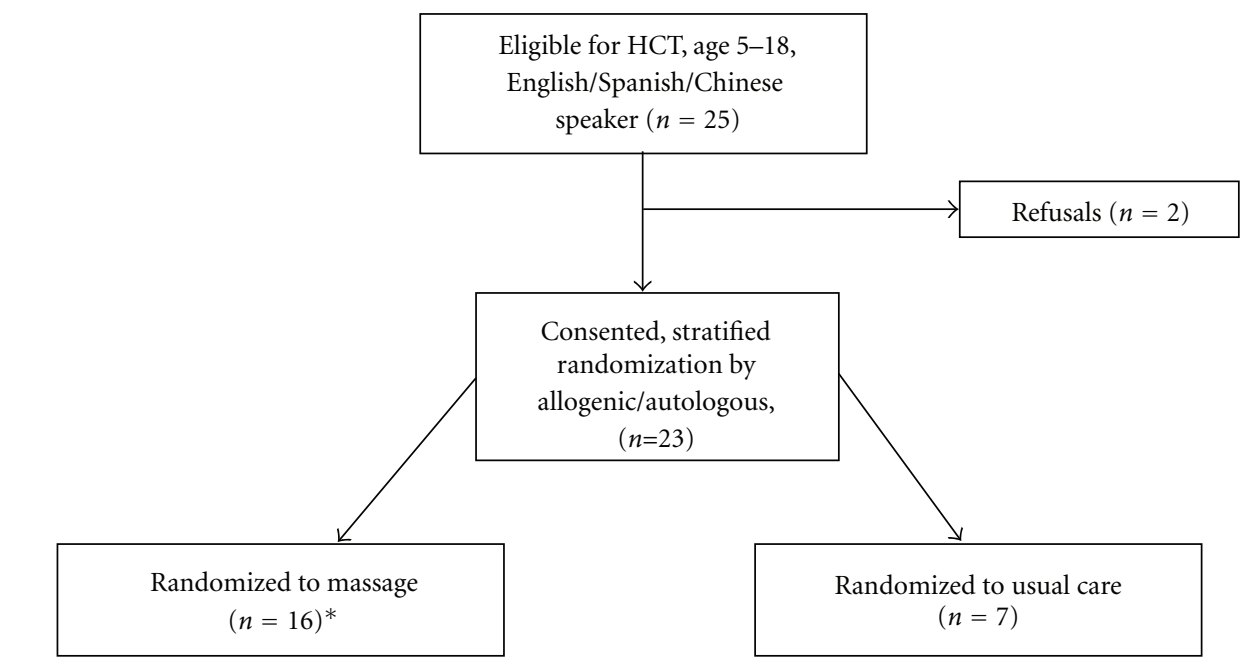

* assessment included medical records for $n=16$, but self-report data were missing on $n=1$ due to a temporary lapse of IRB approval

Figure 1: Participant flow chart.

Results for key symptoms as reported in the nurse's daily notes are summarized in Table 2 . None of the symptoms showed statistically significant improvements in the massage/acupressure group. However, we did find some largeto-moderate effect sizes (ES) in favor of the intervention in several important outcomes. Based on nurse's data, children in the intervention group had fewer days of mucositis $(\mathrm{ES}=0.63)$ and lower overall symptom burden $(\mathrm{ES}=$ 0.26). Data from the child's self-report also did not show statistically significant benefits for the massage group, but showed a trend toward improved fatigue, ES $=0.86$, $P=0.08$. In addition the intervention group reported fewer moderate/severe symptoms in a summary measure of fatigue, pain, and nausea $(E S=0.62)$ and decreased pain $(\mathrm{ES}=0.42)$. There were no statistically significant betweengroup differences in duration of hospital stay or days to engraftment.

Findings related to psychological outcome measures (Tables 3(a) and 3(b)) are reported using change scores. The intervention group showed more self-reported beneficial changes for depression (ES $=-0.45$ ) and contentness/serenity (ES $=+0.50)$. Sleep was reported to have changed in a negative direction in the intervention group ( $\mathrm{ES}=-0.96)$; likely a spurious finding, as a worsening of sleep as a result of our intervention does not make sense and was not confirmed in qualitative interviews. Parental outcomes of self-efficacy, perceived stress, posttraumatic stress symptoms, and mood showed no differences between groups at the time of hospital discharge.

\section{Discussion}

Our results demonstrated the feasibility of providing and studying a combined Swedish massage and acupressure in- tervention in a pediatric HCT unit. While the sample size was small, the data suggested some efficacy of the massage/acupressure intervention, particularly related to a reduction in days with mucositis, improvements in fatigue, and reduced pain and loss of appetite. Use of daily nurse's clinical data combined with biweekly self-report data from both children and parents provided multiple perspectives on the clinical efficacy of the intervention for our key outcomes. While the effect sizes we observed are encouraging, the results must be interpreted cautiously given the small sample size and lack of statistically significant differences between groups. A larger study would be needed to determine whether the effect sizes suggested in this pilot study can be confirmed with statistically significant results. Based on our results for a key study outcome-the summary score of the three key symptoms of pain, nausea, and fatigue $(E S=0.62)$, the study would have required at least 64 participants in each group to show a statistically significant difference.

The feasibility of the study was further supported by enthusiastic qualitative data obtained from parent interviews and nurses' reports. These findings are reported separately in a detailed qualitative report (manuscript submitted) [68, 69].

There are a number of unique aspects of the present pilot study compared to other studies in the field of massage and pediatric oncology. The present pilot tested an integration of Eastern and Western massage styles, as is increasingly practiced in the United States. The potential benefits include the relaxing aspects of Swedish massage [1,33] combined with the potential efficacy of acupoint therapy for pain, nausea, and other symptom relief [22]. To our knowledge, there are no comparable studies that have tested an integration of Eastern and Western massage. Involvement of parents in providing additional nonprofessional massages is another innovative feature of our intervention with the 
TABLE 2

(a) Symptoms from the nurses records over 29 days ( 7 days before to 21 days after transplant). Intervention (I; $N=16)$ versus control $(\mathrm{C} ; N=7)$.

\begin{tabular}{|c|c|c|c|c|}
\hline Symptom (scale range) & Arm & Mean \pm SD & ES & $p^{\circ}$ \\
\hline Days of pain $>3$ (on $0-10$ scale) & $\begin{array}{l}\mathrm{I} \\
\mathrm{C}\end{array}$ & $\begin{array}{l}7.8 \pm 4.9 \\
8.0 \pm 5.5\end{array}$ & 0.04 & 0.93 \\
\hline Days of vomiting & $\begin{array}{l}\mathrm{I} \\
\mathrm{C}\end{array}$ & $\begin{array}{l}5.7 \pm 4.6 \\
5.2 \pm 5.0\end{array}$ & 0.11 & 0.82 \\
\hline Days of mucositis & $\begin{array}{l}\mathrm{I} \\
\mathrm{C}\end{array}$ & $\begin{array}{c}9.9 \pm 7.1 \\
14.7 \pm 8.9\end{array}$ & 0.63 & 0.18 \\
\hline $\begin{array}{l}\text { Immune recovery } \\
\text { (Days until } 3 \text { days of WBC > 500) }\end{array}$ & $\begin{array}{l}\mathrm{I} \\
\mathrm{C}\end{array}$ & $\begin{array}{c}17.1 \pm 5.1 \\
17.9 \pm 10.1\end{array}$ & 0.12 & 0.85 \\
\hline $\begin{array}{l}\text { Days with high symptom burden (pain } \\
>3 \text {, nausea, mucositis, and vomiting) }{ }^{1}\end{array}$ & $\mathrm{I}$ & $\begin{array}{l}1.8 \pm 0.5 \\
2.0 \pm 0.6\end{array}$ & 0.26 & 0.57 \\
\hline
\end{tabular}

(b) Symptoms from child self-report: at baseline and 1 week after transplant. Intervention (I; $N=15)$ versus control $(\mathrm{C} ; N=7)$.

\begin{tabular}{|c|c|c|c|c|c|}
\hline \multirow{2}{*}{ Symptom (scale range) } & \multirow[t]{2}{*}{ Arm } & \multicolumn{2}{|c|}{ Mean \pm SD } & \multirow[t]{2}{*}{ ES } & \multirow[t]{2}{*}{$p^{\circ}$} \\
\hline & & Before & After & & \\
\hline Nausea and vomiting ${ }^{1}(0-4)$ & $\begin{array}{l}\mathrm{I} \\
\mathrm{C}\end{array}$ & $\begin{array}{l}0.3 \pm 0.7 \\
1.1 \pm 1.3\end{array}$ & $\begin{array}{l}2.3 \pm 1.5 \\
2.3 \pm 1.5\end{array}$ & +0.01 & 0.98 \\
\hline Loss of appetite ${ }^{1}(0-4)$ & $\begin{array}{l}\mathrm{I} \\
\mathrm{C}\end{array}$ & $\begin{array}{l}1.3 \pm 0.7 \\
2.0 \pm 1.7\end{array}$ & $\begin{array}{l}2.8 \pm 1.5 \\
3.3 \pm 1.0\end{array}$ & +0.36 & 0.44 \\
\hline Feeling tired/run down ${ }^{1}(0-4)$ & $\begin{array}{l}\mathrm{I} \\
\mathrm{C}\end{array}$ & $\begin{array}{l}1.5 \pm 1.3 \\
1.0 \pm 0.8\end{array}$ & $\begin{array}{l}1.9 \pm 1.3 \\
3.0 \pm 1.0\end{array}$ & +0.86 & 0.08 \\
\hline $\operatorname{Pain}^{1}(0-4)$ & $\begin{array}{l}\mathrm{I} \\
\mathrm{C}\end{array}$ & $\begin{array}{l}0.8 \pm 1.0 \\
1.3 \pm 1.5\end{array}$ & $\begin{array}{l}1.2 \pm 1.2 \\
1.6 \pm 0.8\end{array}$ & +0.42 & 0.37 \\
\hline $\begin{array}{l}\text { Summary score of } 3 \text { moderate/severe } \\
\text { symptoms of fatigue, pain, and } \\
\text { nausea }^{1^{* *}}(0-3)\end{array}$ & $\begin{array}{l}\mathrm{I} \\
\mathrm{C}\end{array}$ & $\begin{array}{l}0.3 \pm 0.4 \\
0.3 \pm 0.8\end{array}$ & $\begin{array}{c}1.1+1.1 \\
1.7+0.8\end{array}$ & +0.62 & 0.23 \\
\hline
\end{tabular}

\footnotetext{
${ }^{1}$ Higher score: worse symptoms.

*ES: standardized effect sizes (“+” ES is advantage for intervention; “-” ES is advantage for control).

${ }^{\circ} t$-test.

SD: standard deviation.

**Sum of moderate or severe ("quite a bit/very much" versus "none/a little/somewhat") symptoms of fatigue, nausea, and pain, 1 week self-report (range: 0-3 symptoms).

All measures were from the BASES questionnaire except pain was measured using the Peds quality of life scale.
}

added benefits of increasing the massage dose, supporting timely symptom management and enabling parents to help their children directly.

A previous single-site pilot study performed by Phipps and colleagues [16] demonstrated promising results in improved symptom management, but these results were not confirmed in a larger multisite study [17]. The intervention used in this larger study, a combination of a laugh cart, a guided relaxation and Western massage was substantially different from the present study, with most overlap in the shared aim of reducing child discomfort by nonpharmacological means. The present study may have benefited from the additional use of acupressure, which may account for the moderate-to-high effect sizes for some symptoms compared to this prior study.

Another small feasibility study in 17 children with cancer who were undergoing chemotherapy used a crossover design in which 4 weekly massage sessions alternated with 4 weekly quiet-time control session. This study found that massage was more effective than quiet time at reducing heart rate and anxiety in children less than 14 years but did not show improvements in pain, nausea, or fatigue [70]. The authors concluded that massage in children with cancer is feasible and appears to decrease anxiety. The present study also showed feasibility, but otherwise found different results with moderate ES for a decrease in pain and fatigue and less improved anxiety in the intervention group compared to controls. The addition of acupressure in the present study may have improved symptom management over the previous study, but sample sizes are small in both studies.

Finally, a randomized feasibility study of acupressure in preventing chemotherapy-associated nausea by Jones and colleagues was conducted among 21 pediatric oncology patients, ages 5 to 19 years, using wrist bands compared to placebo bands [71]. Acupressure applied using wrist bands was feasible and well tolerated but there were not statistically significant results compared to placebo, potentially due to small sample size. While Jones's study used a bead to apply 
TABLE 3

(a) Changes in negative affect from baseline to 1 week after transplant. Mean "+" change indicates worsening; mean "-" change indicates improvement; ES “-” indicates benefit for intervention compared with control; ES “+” vice versa.

\begin{tabular}{|c|c|c|c|c|c|c|}
\hline \multirow{2}{*}{ Symptom change (scale range) } & \multirow[t]{2}{*}{ Arm } & \multicolumn{3}{|c|}{ Means \pm SD } & \multirow[t]{2}{*}{ ES } & \multirow[t]{2}{*}{$p^{\circ}$} \\
\hline & & Before & After & Change & & \\
\hline $\begin{array}{l}\text { Depression }^{1}(0-4) \\
\text { by child report }\end{array}$ & $\begin{array}{l}\mathrm{I} \\
\mathrm{C}\end{array}$ & $\begin{array}{l}0.7 \pm 0.9 \\
0.7 \pm 0.8\end{array}$ & $\begin{array}{l}0.9 \pm 1.1 \\
1.4 \pm 1.0\end{array}$ & $\begin{array}{l}+0.2 \pm 1.1 \\
+0.7 \pm 1.1\end{array}$ & -0.45 & 0.33 \\
\hline $\begin{array}{l}\text { Anxiety }^{1}(0-4) \\
\text { by child report }\end{array}$ & $\mathrm{I}$ & $\begin{array}{l}0.9 \pm 1.0 \\
1.4 \pm 1.1\end{array}$ & $\begin{array}{l}0.6 \pm 1.0 \\
0.7 \pm 0.8\end{array}$ & $\begin{array}{l}-0.3 \pm 0.9 \\
-0.7 \pm 1.0\end{array}$ & +0.42 & 0.37 \\
\hline $\begin{array}{l}\text { Worry }{ }^{1}(0-4) \\
\text { by child report }\end{array}$ & $\begin{array}{l}\mathrm{I} \\
\mathrm{C}\end{array}$ & $\begin{array}{l}1.4 \pm 1.1 \\
1.7 \pm 1.4\end{array}$ & $\begin{array}{l}1.4 \pm 1.2 \\
1.3 \pm 1.3\end{array}$ & $\begin{array}{l}-0.0 \pm 1.2 \\
-0.4 \pm 1.2\end{array}$ & +0.32 & 0.50 \\
\hline $\begin{array}{l}\text { Complaining/demanding }{ }^{1}(0-4) \\
\text { by parent report }\end{array}$ & $\begin{array}{l}\mathrm{I} \\
\mathrm{C}\end{array}$ & $\begin{array}{l}2.4 \pm 1.5 \\
2.0 \pm 1.5\end{array}$ & $\begin{array}{l}2.1 \pm 1.0 \\
2.1 \pm 1.2\end{array}$ & $\begin{array}{l}-0.3 \pm 1.7 \\
+0.1 \pm 0.7\end{array}$ & -0.45 & 0.21 \\
\hline
\end{tabular}

(b) Changes in positive affect and sleep quality from baseline to 1 week after transplant. Mean "+" change indicates improving; mean "_" change indicates worsening; ES “+” indicates benefit for intervention compared with control; ES “-" vice versa.

\begin{tabular}{|c|c|c|c|c|c|c|}
\hline \multirow{2}{*}{ Symptom change (scale range) } & \multirow[t]{2}{*}{ Arm } & \multicolumn{3}{|c|}{ Means \pm SD } & \multirow[t]{2}{*}{ ES } & \multirow[t]{2}{*}{$p^{\circ}$} \\
\hline & & Before & After & Change & & \\
\hline $\begin{array}{l}\text { Contentness/serenity }{ }^{2}(0-4) \\
\text { by child report }\end{array}$ & $\begin{array}{l}\mathrm{I} \\
\mathrm{C}\end{array}$ & $\begin{array}{l}2.3 \pm 1.4 \\
2.1 \pm 1.3\end{array}$ & $\begin{array}{l}2.2 \pm 1.5 \\
1.3 \pm 0.8\end{array}$ & $\begin{array}{l}-0.1 \pm 1.6 \\
-0.9 \pm 1.1\end{array}$ & +0.50 & 0.29 \\
\hline $\begin{array}{l}\text { Overall mood } \operatorname{mo}^{2}(0-4) \\
\text { by child report }\end{array}$ & $\begin{array}{l}\mathrm{I} \\
\mathrm{C}\end{array}$ & $\begin{array}{l}2.8 \pm 0.9 \\
2.9 \pm 0.7\end{array}$ & $\begin{array}{l}2.3 \pm 0.9 \\
2.3 \pm 1.0\end{array}$ & $\begin{array}{l}-0.4 \pm 1.2 \\
-0.6 \pm 0.8\end{array}$ & +0.20 & 0.72 \\
\hline $\begin{array}{l}\text { Sleep }^{3}(0-4) \\
\text { by child report }\end{array}$ & $\begin{array}{l}\mathrm{I} \\
\mathrm{C}\end{array}$ & $\begin{array}{l}2.7 \pm 1.1 \\
2.3 \pm 1.0\end{array}$ & $\begin{array}{l}2.4 \pm 1.3 \\
2.7 \pm 0.8\end{array}$ & $\begin{array}{l}-0.3 \pm 0.8 \\
+0.4 \pm 0.5\end{array}$ & -0.96 & 0.05 \\
\hline
\end{tabular}

${ }^{1}$ Higher score: worse negative affect.

${ }^{2}$ Higher score: higher positive affect.

${ }^{3}$ Higher score: better sleep.

* ES: standardized effect sizes.

${ }^{\circ} t$-test.

I: intervention, C: control.

SD: Standard Deviation.

(Sample $N$ for intervention (I) versus control (C); intention to treat: 15 versus 7).

pressure on one acupoint, it differed from the present study, in which acupressure was provided by experienced practitioners who used multiple points.

The finding that the intervention may have reduced days with mucositis and reduced tiredness, although at first surprising, may in fact reflect a potential mechanism of action that has been suggested by results from prior acupoint studies, namely, a reduction in proinflammatory cytokines such as TNF- $\alpha$, IL-1, and IL-6 [72]. These proinflammatory cytokines are increased during chemotherapy, probably due to high levels of apoptosis (programmed cell death). Some of these proinflammatory cytokines, in turn, are hypothesized to be important factors in chemotherapy-related fatigue [73] and mucositis [74]. This hypothetical mechanism may deserve further investigation in a larger trial with the addition of biological samples.

The present study focused on longer-term changes in symptoms (assessed every other week from self-report or daily by the nurses) rather than short-term changes (minutes or hours) after the intervention. This design allowed us to assess only the more enduring effects of massage, but not the immediate effects. Future studies might benefit from both short- and longer-term assessments. Short-term benefits from massage have been reported in other studies [75] and appear to be more consistent than longer-term effects.
Limitations of this feasibility study include the small sample size and the limited number of time points for selfreport assessments. In addition, the dose of the massage intervention averaged 1.8 massages per week, while the target dose was 3 per week. This difference occurred in part because of scheduling difficulties related to periods of time with severe symptoms, unscheduled naps, and high health care demands. Participants often preferred massage sessions in the evening when medical procedures were over, but massage providers had limited evening availability. Finite resources made it difficult to ensure wider availability of the massage provider. Based on our results, we believe that an increased dose of massage would be facilitated by having a provider regularly available during the late afternoon and evening for several hours per day (rather than individually scheduled visits).

Major strengths of the study include the feasibility and acceptability of a massage/acupressure study on a busy pediatric stem cell transplant unit, indications of efficacy of the intervention, the lack of side effects, and the enthusiastic support for the intervention by the involved pediatricians, nurses, and parents $[68,69]$.

This study provided new data on the efficacy of combined Swedish massage and acupressure for improved symptom management in children undergoing hematopoietic cell 
transplants. Findings from this and larger future studies have the potential to influence clinical practice related to stem cell transplant-associated symptoms in children by introducing massage and acupressure, an ancient healing modality, into a "high-tech" pediatric hospital setting. Massage and acupressure for symptom management are attractive, given their potential to treat multiple symptoms with few or no side effects. Future studies should enroll sufficient numbers to better test the efficacy of combined Swedish massage and acupressure in symptom management of pediatric hematopoietic stem cell transplant.

\section{Acknowledgments}

The authors thank the children and parents who took part in this study; the Community Foundation Sonoma County, Santa Rosa California that sponsored the study; massage/acupressure practitioners Marcia Degelman, Paula Koepke, and Jnani Chapman; research assistants Kristina Kavanau, Viranjini Gopisetty, and Derek Ramsey; the nurses on the children's hospital's transplant unit with Trish Murphy and Sara Okane as nurse coordinators. Wolf E. Mehling and E. Anne Lown contributed equally to this paper.

\section{References}

[1] B. R. Cassileth and A. J. Vickers, "Massage therapy for symptom control: outcome study at a major cancer center," Journal of Pain and Symptom Management, vol. 28, no. 3, pp. 244-249, 2004.

[2] P. A. Cassileth, J. Andersen, H. M. Lazarus et al., "Autologous bone marrow transplant in acute myeloid leukemia in first remission," Journal of Clinical Oncology, vol. 11, no. 2, pp. 314319, 1993.

[3] L. Grealish, A. Lomasney, and B. Whiteman, "Foot massage: a nursing intervention to modify the distressing symptoms of pain and nausea in patients hospitalized with cancer," Cancer Nursing, vol. 23, no. 3, pp. 237-243, 2000.

[4] M. Hernandez-Reif, G. Ironson, T. Field et al., "Breast cancer patients have improved immune and neuroendocrine functions following massage therapy," Journal of Psychosomatic Research, vol. 57, no. 1, pp. 45-52, 2004.

[5] D. Fellowes, K. Barnes, and S. Wilkinson, "Aromatherapy and massage for symptom relief in patients with cancer," Cochrane Database of Systematic Reviews, no. 2, Article ID CD002287, 2004.

[6] J. Post-White, M. E. Kinney, K. Savik, J. B. Gau, C. Wilcox, and I. Lerner, "Therapeutic massage and healing touch improve symptoms in cancer," Integrative Cancer Therapies, vol. 2, no. 4, pp. 332-344, 2003.

[7] A. Billhult, I. Bergbom, and E. Stener-Victorin, "Massage relieves nausea in women with breast cancer who are undergoing chemotherapy," Journal of Alternative and Complementary Medicine, vol. 13, no. 1, pp. 53-57, 2007.

[8] A. Billhult and K. Dahlberg, "A meaningful relief from suffering: experiences of massage in cancer care," Cancer Nursing, vol. 24, no. 3, pp. 180-184, 2001.

[9] L. Corbin, "Safety and efficacy of massage therapy for patients with cancer," Cancer Control, vol. 12, no. 3, pp. 158-164, 2005.

[10] P. van der Riet, "Massaged embodiment of cancer patients,"
The Australian Journal of Holistic Nursing, vol. 6, no. 1, pp. 413, 1999.

[11] W. E. Mehling, B. Jacobs, M. Acree et al., "Symptom management with massage and acupuncture in postoperative cancer patients: a randomized controlled trial," Journal of Pain and Symptom Management, vol. 33, no. 3, pp. 258-266, 2007.

[12] J. S. Kutner, M. C. Smith, L. Corbin et al., "Massage therapy versus simple touch to improve pain and mood in patients with advanced cancer: a randomized trial," Annals of Internal Medicine, vol. 149, no. 6, pp. 369-379, 2008.

[13] S. Beider and C. A. Moyer, "Randomized controlled trials of pediatric massage: a review," Evidence-Based Complementary and Alternative Medicine, vol. 4, no. 1, pp. 23-34, 2007.

[14] T. Field, "Massage therapy," Medical Clinics of North America, vol. 86, no. 1, pp. 163-171, 2002.

[15] T. A. Ahles, D. M. Tope, B. Pinkson et al., "Massage therapy for patients undergoing autologous bone marrow transplantation," Journal of Pain and Symptom Management, vol. 18, no. 3, pp. 157-163, 1999.

[16] S. Phipps, "Reduction of distress associated with paediatric bone marrow transplant: complementary health promotion interventions," Pediatric Rehabilitation, vol. 5, no. 4, pp. 223234, 2002.

[17] S. Phipps, M. Barrera, K. Vannatta, X. Xiong, J. J. Doyle, and M. A. Alderfer, "Complementary therapies for children undergoing stem cell transplantation: report of a multisite trial," Cancer, vol. 116, no. 16, pp. 3924-3933, 2010.

[18] A. C. Mertens, S. Sencer, C. D. Myers et al., "Complementary and alternative therapy use in adult survivors of childhood cancer: a report from the childhood cancer survivor study," Pediatric Blood and Cancer, vol. 50, no. 1, pp. 90-97, 2008.

[19] C. D. Myers, T. Walton, L. Bratsman, J. Wilson, and B. Small, "Massage modalities and symptoms reported by cancer patients: narrative review," Journal of the Society for Integrative Oncology, vol. 6, no. 1, pp. 19-28, 2008.

[20] American Massage Therapy Association, "Member survey 2003," 2003, http://www.amtamassage.org/ (accessed 5/17/2011).

[21] J. Ezzo, K. Streitberger, and A. Schneider, "Cochrane systematic reviews examine P6 acupuncture-point stimulation for nausea and vomiting," Journal of Alternative and Complementary Medicine, vol. 12, no. 5, pp. 489-495, 2006.

[22] J. M. Ezzo, M. A. Richardson, A. Vickers et al., "Acupuncturepoint stimulation for chemotherapy-induced nausea or vomiting," Cochrane Database of Systematic Reviews, no. 2, Article ID CD002285, 2006.

[23] S. L. Dibble, J. Chapman, K. A. Mack, and A. S. Shih, "Acupressure for nausea: results of a pilot study," Oncology Nursing Forum, vol. 27, no. 1, pp. 41-47, 2000.

[24] L. F. Chao, A. L. Zhang, H. E. Liu, M. H. Cheng, H. B. Lam, and S. K. Lo, "The efficacy of acupoint stimulation for the management of therapy-related adverse events in patients with breast cancer: a systematic review," Breast Cancer Research and Treatment, vol. 118, no. 2, pp. 255-267, 2009.

[25] G. Gardani, R. Cerrone, C. Biella et al., "A progress study of 100 cancer patients treated by acupressure for chemotherapyinduced vomiting after failure with the pharmacological approach," Minerva Medica, vol. 98, no. 6, pp. 665-668, 2007.

[26] A. Molassiotis, P. Sylt, and H. Diggins, "The management of cancer-related fatigue after chemotherapy with acupuncture and acupressure: a randomised controlled trial," Complementary Therapies in Medicine, vol. 15, no. 4, pp. 228-237, 2007. 
[27] T. Sundberg, J. Halpin, A. Warenmark, and T. Falkenberg, "Towards a model for integrative medicine in Swedish primary care," BMC Health Services Research, vol. 7, article 107, 2007.

[28] T. Sundberg, M. Petzold, P. Wändell, A. Rydén, and T. Falkenberg, "Exploring integrative medicine for back and neck pain - a pragmatic randomised clinical pilot trial," BMC Complementary and Alternative Medicine, vol. 9, p. 33, 2009.

[29] K. J. Sherman, M. W. Dixon, D. Thompson, and D. C. Cherkin, "Development of a taxanomy to descirbe massage treatments for musculoskeletal pain," BMC Complementary and Alternative Medicine, vol. 6, article 24, 2006.

[30] Y. H. Shin, T. I. Kim, M. S. Shin, and H. S. Juon, "Effect of acupressure on nausea and vomiting during chemotherapy cycle for Korean postoperative stomach cancer patients," Cancer Nursing, vol. 27, no. 4, pp. 267-274, 2004.

[31] L. S. Dune and S. Y. Shiao, "Metaanalysis of acustimulation effects on postoperative nausea and vomiting in children," Explore, vol. 2, no. 4, pp. 314-320, 2006.

[32] A. Billhult and S. Maatta, "Light pressure massage for patients with severe anxiety," Complementary Therapies in Clinical Practice, vol. 15, no. 2, pp. 96-101, 2009.

[33] A. T. Ferrell-Torry and O. J. Glick, "The use of therapeutic massage as a nursing intervention to modify anxiety and the perception of cancer pain," Cancer Nursing, vol. 16, no. 2, pp. 93-101, 1993

[34] S. W. Jane, D. J. Wilkie, B. B. Gallucci, R. D. Beaton, and H. Y. Huang, "Effects of a full-body massage on pain intensity, anxiety, and physiological relaxation in Taiwanese patients with metastatic bone pain: a pilot study," Journal of Pain and Symptom Management, vol. 37, no. 4, pp. 754-763, 2009.

[35] S. W. Jane, D. J. Wilkie, B. B. Gallucci, and R. D. Beaton, "Systematic review of massage intervention for adult patients with cancer: a methodological perspective," Cancer Nursing, vol. 31, no. 6, pp. E24-E35, 2008.

[36] J. Corner, N. Cawley, and S. Hildebrand, "An evaluation of the use of massage and essential oils on the wellbeing of cancer patients," International Journal of Palliative Nursing, vol. 1, no. 2, pp. 67-73, 1995.

[37] J. E. Sanders, "Bone marrow transplantation in pediatric oncology," in Principles and Practice of Pediatric Oncology, P. A. Pizzo and D. G. Poplack, Eds., pp. 357-374, Cippincott-Raven, Philadelphia, Pa, USA, 3rd edition, 1997.

[38] Y. Kim and R. Schulz, "Family caregivers' strains: comparative analysis of cancer caregiving with dementia, diabetes, and frail elderly caregiving," Journal of Aging and Health, vol. 20, no. 5, pp. 483-503, 2008.

[39] G. Magni et al., "Longitudinal evaluations of pyschological distress in parents of children with malignancies," Acta Paediatrica Scandinavica, vol. 75, pp. 283-288, 1986.

[40] B. Fife, J. Norton, and G. Groom, “The family's adaptation to childhood leukemia," Social Science and Medicine, vol. 24, no. 2, pp. 159-168, 1987.

[41] P. Sloper, "Predictors of distress in parents of children with cancer: a prospective study," Journal of Pediatric Psychology, vol. 25, no. 2, pp. 79-91, 2000.

[42] A. E. Kazak, "Evidence-based interventions for survivors of childhood cancer and their families," Journal of Pediatric Psychology, vol. 30, no. 1, pp. 29-39, 2005.

[43] U. Pöder, G. Ljungman, and L. von Essen, "Posttraumatic stress disorder among parents of children on cancer treatment: a longitudinal study," Psycho-Oncology, vol. 17, no. 5, pp. 430437, 2008.
[44] A. E. Kazak, M. Alderfer, M. T. Rourke, S. Simms, R. Streisand, and J. R. Grossman, "Posttraumatic stress disorder (PTSD) and posttraumatic stress symptoms (PTSS) in families of adolescent childhood cancer survivors," Journal of Pediatric Psychology, vol. 29, no. 3, pp. 211-219, 2004.

[45] B. L. Green and R. Kimerling, "Trauma, posttraumatic stress disorder, and health status," in Trauma and Health, Physical Health Consequences of Exposure to Extreme Stress, P. P. Schnurr and B. L. Green, Eds., pp. 247-276, American Psychological Association, Washington, DC, USA, 2004.

[46] American Psychiatric Association, DSM-IV: Diagnostic and Statistical Manual of Mental Disorders, American Psychiatric Association, Washington, DC, USA, 1994.

[47] M. L. Stuber, A. E. Kazak, K. Meeske et al., "Predictors of posttraumatic stress symptoms in childhood cancer survivors," Pediatrics, vol. 100, no. 6, pp. 958-964, 1997.

[48] A. D. Blotcky, J. M. Raczynski, R. Gurwitch, and K. Smith, "Family influences on hopelessness among children early in the cancer experience," Journal of Pediatric Psychology, vol. 10, no. 4, pp. 479-493, 1985.

[49] R. T. Brown, N. J. Kaslow, A. Madan-Swain, K. J. Doepke, S. B. Sexson, and L. J. Hill, "Parental psychopathology and children's adjustment to leukemia," Journal of the American Academy of Child and Adolescent Psychiatry, vol. 32, no. 3, pp. 554-561, 1993.

[50] M. J. Dolgin and S. Phipps, "Reciprocal influences in family adjustment to childhood cancer," in Cancer and the Family, C. Cooper, A. Kaplan, and A. de-Nour, Eds., John Wiley \& Sons, Oxford, UK, 1996.

[51] T. Field, "Massage therapy for infants and children," Journal of Developmental and Behavioral Pediatrics, vol. 16, no. 2, pp. 105-111, 1995.

[52] S. J. Rexilius, C. Mundt, M. Erickson Megel, and S. Agrawal, "Therapeutic effects of massage therapy and handling touch on caregivers of patients undergoing autologous hematopoietic stem cell transplant," Oncology Nursing Forum, vol. 29, no. 3, pp. E35-E44, 2002.

[53] J. H. Barlow, L. A. Powell, M. Gilchrist, and M. Fotiadou, "The effectiveness of the training and support program for parents of children with disabilities: a randomized controlled trial," Journal of Psychosomatic Research, vol. 64, no. 1, pp. 55-62, 2008.

[54] J. H. Barlow, L. A. Cullen-Powell, and H. Williams, "The training \& support programme for parents of children with ataxia: a pilot study," Psychology, Health and Medicine, vol. 12, no. 1, pp. 64-69, 2007.

[55] H. L. Williams, L. A. Cullen, and J. H. Barlow, "The psychological well-being and self-efficacy of carers of children with disabilities following attendance on a simple massage training and support programme: a 12-month comparison study of adherers and non-adherers," Complementary Therapies in Medicine, vol. 13, no. 2, pp. 107-114, 2005.

[56] K. Streitberger, J. Ezzo, and A. Schneider, "Acupuncture for nausea and vomiting: an update of clinical and experimental studies," Autonomic Neuroscience, vol. 129, no. 1-2, pp. 107$117,2006$.

[57] Shanghai College of Traditional Medicine, Acupuncture, A Comprehensive Text, Eastland Press Incorporated, Seattle, Wash, USA, 1981.

[58] G. Maciocia, The Foundations of Chinese Medicine: A Comprehensive Text for Acupouncturists and Herbalists, Churchill Livingstone, London, UK, 1989.

[59] S. Phipps, M. Dunavant, D. Jayawardene, and D. K. Srivastiva, "Assessment of health-related quality of life in acute in-patient 
settings: use of the bases instrument in children undergoing bone marrow transplantation," International Journal of Cancer, vol. 83, no. 12, pp. 18-24, 1999.

[60] S. Phipps, P. S. Hinds, S. Channell, and G. L. Bell, "Measurement of behavioral, affective, and somatic responses to pediatric bone marrow transplantation: development of the BASES scale," Journal of Pediatric Oncology Nursing, vol. 11, no. 3, pp. 109-119, 1994.

[61] J. W. Varni, T. M. Burwinkle, and E. R. Katz, "The PedsQL in pediatric cancer pain: a prospective longitudinal analysis of pain and emotional distress," Journal of Developmental and Behavioral Pediatrics, vol. 25, no. 4, pp. 239-246, 2004.

[62] J. W. Varni, T. M. Burwinkle, E. R. Katz, K. Meeske, and P. Dickinson, "The PedsQL in pediatric cancer: reliability and validity of the pediatric quality of life inventory generic core scales, multidimensional fatigue scale, and cancer module," Cancer, vol. 94, no. 7, pp. 2090-2106, 2002.

[63] B. L. Fredrickson, M. M. Tugade, C. E. Waugh, and G. R. Larkin, "What good are positive emotions in crises? A prospective study of resilience and emotions following the terrorist attacks on the United States on September 11th, 2001," Journal of Personality and Social Psychology, vol. 84, no. 2, pp. 365-376, 2003.

[64] L. Radloff, "The CES-D scale: a self-report depression scale for research in the general population," Applied Psychological Measurement, vol. 1, pp. 385-401, 1977.

[65] A. B. Shafer, "Meta-analysis of the factor structures of four depression questionnaires: Beck, CES-D, Hamilton, and Zung," Journal of Clinical Psychology, vol. 62, no. 1, pp. 123146, 2006.

[66] E. B. Foa, D. S. Riggs, C. V. Dancu, and B. O. Rothbaum, "Reliability and validity of a brief instrument for assessing post-traumatic stress disorder," Journal of Traumatic Stress, vol. 6, no. 4, pp. 459-473, 1993.

[67] B. F. Fuemmeler, L. L. Mullins, J. Van Pelt, M. Y. Carpentier, and J. Parkhurst, "Posttraumatic stress symptoms and distress among parents of children with cancer," Children's Health Care, vol. 34, no. 4, pp. 289-303, 2005.

[68] S. Ackerman et al., "Massage for children undergoing heematopoietic cell transplantation: a qualitative report," in American Massage Therapy Association, 2010.

[69] E. A. Lown, "Massage provides symptom relief for pediatric stem cell transplant patients: a pilot randomized controlled trial," in Proceedings of the American Psycho-Oncology Society Conference, Anaheim, Calif, USA, 2011.

[70] J. Post-White, M. Fitzgerald, K. Savik, M. C. Hooke, A. B. Hannahan, and S. F. Sencer, "Massage therapy for children with cancer," Journal of Pediatric Oncology Nursing, vol. 26, no. 1, pp. 16-28, 2009.

[71] E. Jones, S. Isom, K. J. Kemper, and T. W. McLean, "Acupressure for chemotherapy-associated nausea and vomiting in children," Journal of the Society for Integrative Oncology, vol. 6, no. 4, pp. 141-145, 2008.

[72] Y. K. Yim, H. Lee, K. E. Hong et al., "Electro-acupuncture at acupoint ST36 reduces inflammation and regulates immune activity in collagen-induced arthritic mice," Evidence-based Complementary and Alternative Medicine, vol. 4, no. 1, pp. 5157, 2007.

[73] J. E. Bower, P. A. Ganz, L. T. May et al., "Inflammatory biomarkers and fatigue during radiation therapy for breast and prostate cancer," Clinical Cancer Research, vol. 15, no. 17, pp. 5534-5540, 2009.

[74] R. M. Logan, A. M. Stringer, J. M. Bowen et al., "The role of pro-inflammatory cytokines in cancer treatment-induced alimentary tract mucositis: pathobiology, animal models and cytotoxic drugs," Cancer Treatment Reviews, vol. 33, no. 5, pp. 448-460, 2007.

[75] C. A. Moyer, J. Rounds, and J. W. Hannum, "A meta-analysis of massage therapy research," Psychological Bulletin, vol. 130, no. 1, pp. 3-18, 2004. 


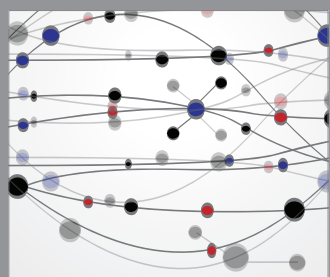

The Scientific World Journal
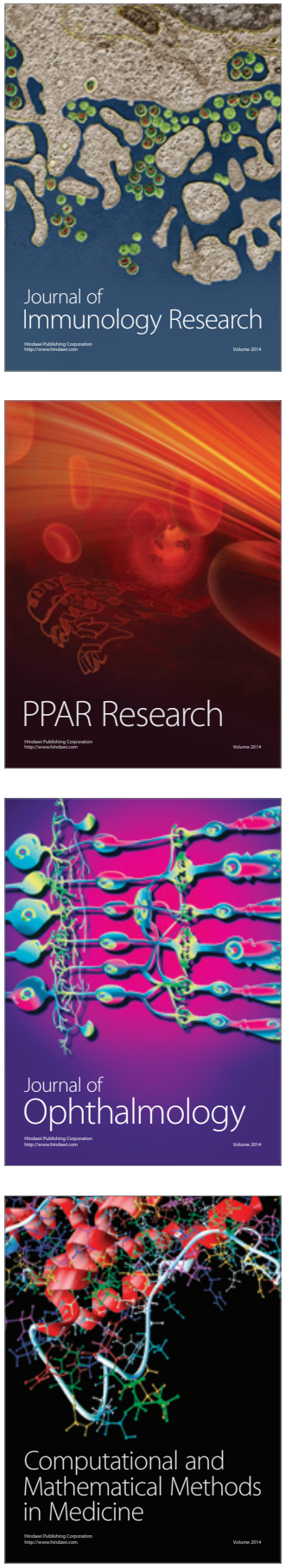

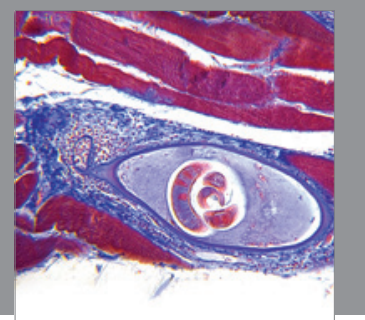

Gastroenterology

Research and Practice
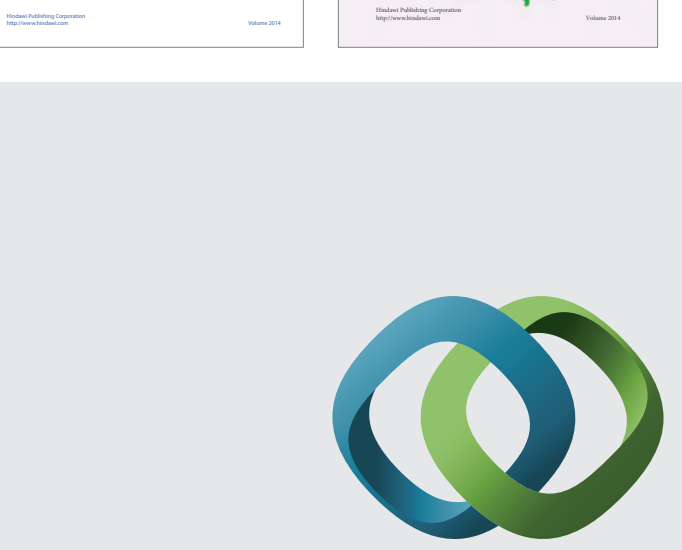

\section{Hindawi}

Submit your manuscripts at

http://www.hindawi.com
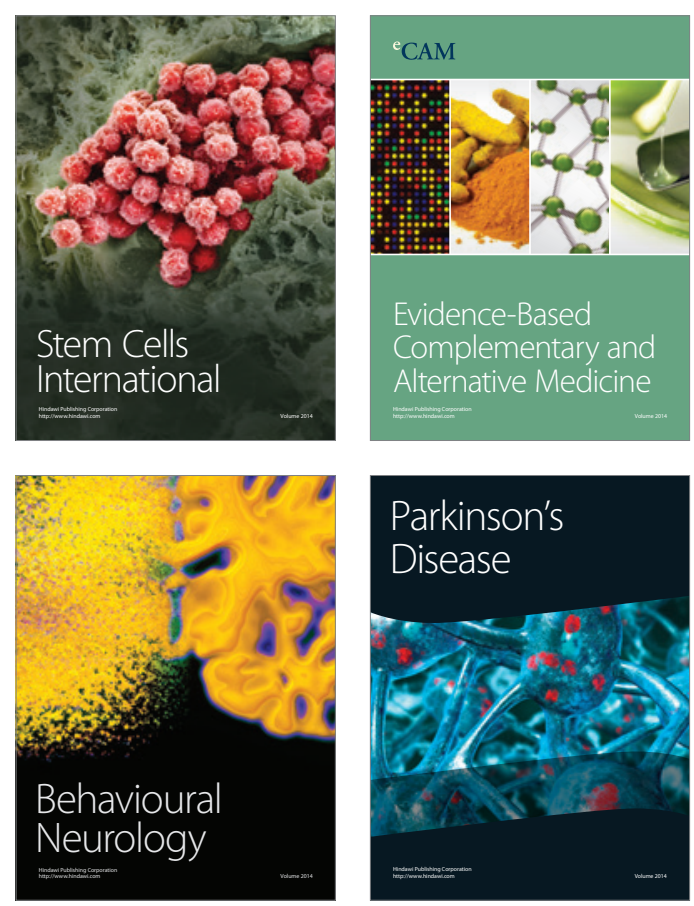

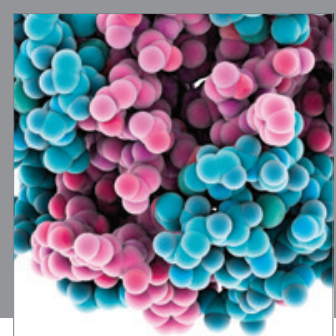

Journal of
Diabetes Research

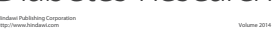

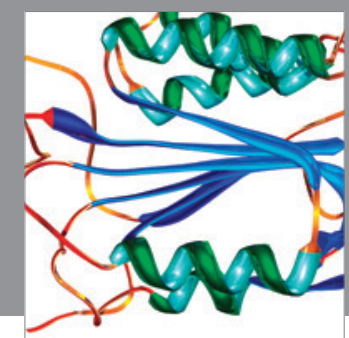

Disease Markers
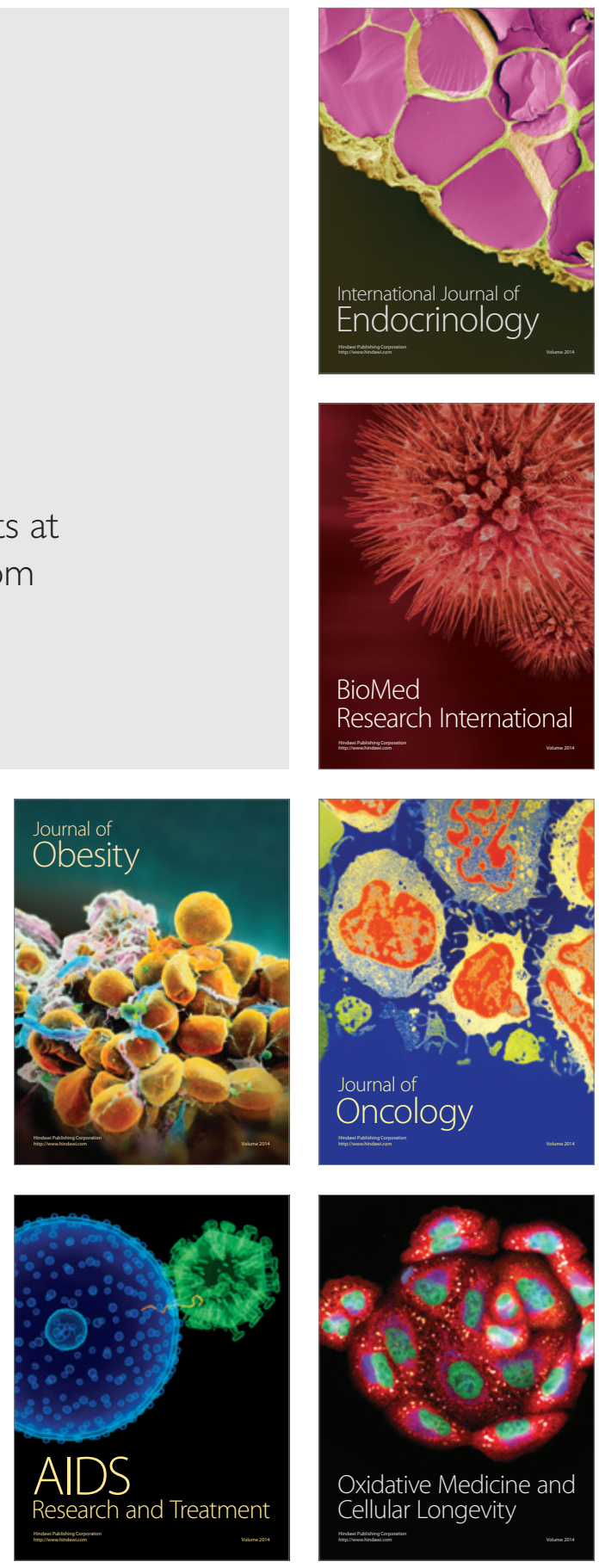